Jurnal Kesehatan Masyarakat
http://journal.unnes.ac.id/nju/index.php/kemas

\title{
AROMATHERAPY GINGER USE IN PATIENTS WITH NAUSEA \& VOMITING ON POST CERVICAL CANCER CHEMOTHERAPY
}

\author{
Iis Sriningsih ${ }^{\bowtie}$, Elisa, Kurniati Puji Lestari \\ Nursing Department, Ministry of Health, Polytechnic of Health Semarang
}

\section{Info Artikel}

Article History:

Submitted March 2017

Accepted July 2017

Published July 2017

Keywords:

Aromatherapy; Nausea;

Vomiting; Cervical

Cancer; Chemotherapy.

\section{DOI}

http://dx.doi.org/10.15294/

kemas.v13i1.5367

\begin{abstract}
Chemotherapy is an effective treatment for cancer. However, it causes some side effects which include nausea and vomiting. More than $70 \%$ of patients experience nausea and vomiting after chemotherapy. The purpose of this study was to determine the effect of ginger aromatherapy in nausea, and vomiting patients on post cervical cancer chemotherapy. We used a pretest-posttest control group design, using purposive sampling of 60 respondents. We used anti-emetics measurement tool according to Multinational Association of Supportive Care in Cancer (MASCC) to assessed patient's complaints. The result showed significant difference in nausea and vomiting group before and after given aromatherapy $(p=0.000)$; nausea score $(p=0.005)$ and vomiting score $(p=0.013)$ from intervention and control group. No significant difference was observed in nausea $(\mathrm{p}=0.279)$, and vomiting $(\mathrm{p}=0.276)$ on control group. Ginger aromatherapy can be used as alternative medication to reduce post-chemotherapy nausea and vomiting.
\end{abstract}

\section{Introduction}

Cervical cancer is caused by Human Papiloma Virus (HPV) infection. It has a high mortality rate. According to International Agency for Research on Cancer (IARC) in 2012, cervical cancer is the third most common cancer in women worldwide with $7.9 \%$ prevalence and $7.5 \%$ mortality rate (Mulyati, 2015). Most cervical cancer patients were diagnosed in late stage of the disease. The current treatment of this disease is chemotherapy. It uses medicines to eliminate or inhibit the development of cancer cells. Chemotherapy can be administered intravenously to reach cancer cells throughout the body or directly to the particular site of cancer.

Chemotherapy is an effective treatment for cancers. Chemotherapy medicines used in $\mathrm{dr}$.
Moewardi General Hospital are 5-fluorouracil (5-FU) and cisplatin. Cisplatin is a level 5 chemotherapy medicine with high nausea effect. The administration of this medicine will not only eliminate cancer cells, but also normal cells. Therefore, it can cause several side effects during, and after the treatment. Side effects of this therapy are fatigue, nausea, vomit, gastrointestinal disturbance, aphthous ulcers, hair fall, numbness sensation in hand, and foot digits, color changing skin, and etc.

Nausea and vomiting are the most common side effects of chemotherapy with prevalence more than $60 \%$ (Susanti, 2012). The study by Klein and Griffiths (Montazeri SA, 2013) showed that nausea and vomiting were the most common side effects of chemotherapy and reported to reach $54-96 \%$. In spite of 
having antiemetic medicines, more than $70 \%$ of patients were complaining about nausea and vomiting after chemotherapy. Based on a study in Sardjito General Hospital (2005), there were $50 \%$ of patients that experience nausea and vomiting after chemotherapy.

Uncontrolled nausea and vomiting can affect the treatment of the patient in general and reduce therapeutical response of cancer patients. Continues nausea, and vomiting reduce therapeutical effect of chemotherapeutic agents. In addition, uncontrolled nausea, and vomiting causes dehydration, electrolyte imbalance, weight loss, and malnutrition. Prolonged vomiting can cause esophageal injury, gastric injury, and bleeding.

Severity and duration of nausea and vomiting are different from each patient depend on the type of chemotherapeutic agent used on patient. Antiemetic medicine has been used for those patients. Typical antiemetic medicine used after chemotherapy are ondansetron and dexamethasone. Ondansetron is an effective antiemetic medicine. However, there are still many patients experiencing nausea after chemotherapy.

There are methods used to control nausea and vomiting after chemotherapy either by pharmacological or complementary therapy (Montazeri, 2013). For pharmacological therapies, it can use antiemetic, antihistamine, and corticosteroid. Complementary therapy such as dietary control, emotional support, ginger aromatherapy, cognitive and behavioral approach, music, yoga, and etc.

Aromatherapy can be used to reduce nausea and vomiting in patient with cancer that received chemotherapy. Its mechanism of actions is conducted through circulation and respiratory system. When an etheric oil is inhaled, the volatile particle will carry its aromatic elements to the nostril. Vibrating hair acts as a receptor inside the nose, will deliver electrochemical impulse to the emotion and memory center. Furthermore, this impulse will be continued throughout the body by circulation system. Smell response produced and will stimulate brain cells. Pleasant smell will stimulate thalamus to secrete enkephalin, that reduce pain and produce calm feeling (Howard, 2007).
Pituitary gland also release chemical agents into bloodstream to regulate other gland function, such as thyroid and adrenal gland. Smell that produce calm feeling will stimulate raphe nucleus of the brain to secrete serotonin and affect sleepiness (Howard, 2007).

\section{Method}

This study used quasy experimental study using aromatherapy as an intervention for cancer patients after chemotherapy. We used pretest-posttest control group design, which involves two subject groups. First group was given an intervention while the second group treated as control. Based on this design, the effect of the intervention to dependent variable was tested by comparing it between intervention and control group.

The aim of this study was to understand the effect of ginger aromatherapy to nausea and vomiting in post chemotherapy patients at Dr. Moewardi Hospital, Surakarta. Sixty patients were involved in this study. Thirty patients in the intervention group were given ondansetron, dexamethasone, and inhaled ginger aromatherapy. Thirty others in the control group were given ondansetron and dexamethasone. Sampling technique used in this study was purposive sampling. Every cervical cancer patients that was treated with 5 days of chemotherapy were included in this study.

Both groups received the same chemotherapy and antiemetic regiments. Chemotherapeutical medicines used for both groups were paxus cisplatin and 5-fluorouracil (5-FU). Antiemetic medicines used for both groups were ondansetron and dexamethasone.

Instrument used for this study was Multinational Association of Supportive Care in Cancer (MASCC) Antiemetic Tool (2004). In this study, the frequency and intensity of nausea and vomiting were measured 24 hours after chemotherapy.

In this study, the patient inhaled ginger aromatherapy using masker device that contained 5 drops of ginger oil for 10 minutes. This procedure was repeated 30 minutes before the patients start eating or feeling nauseous. The measurement of nausea and vomiting were performed twice. In the intervention group, it was performed before and 24 hours after 
administration of aromatherapy. In the control group, it was performed 24 and 48 hours after chemotherapy.

Analysis of data in this study was performed using univariate and bivariate analysis. Univariate analysis described nausea and vomiting in intervention group, before and after the administration of aromatherapy. In control group, it described nausea and vomiting in 24 and 48 hours after chemotherapy.

The difference of nausea and vomiting before and after the administration of aromatherapy (ginger oil) in the intervention group was analyzed using Wilcoxon test due to non-normal data distribution. The difference of nausea and vomiting score between intervention and control group in this study was tested using Mann Whitney test.

\section{Result and Discussion}

The results of this study were presented respectively as following: description of nausea and vomiting, the difference of nausea and vomiting before and after administration of aromatherapy in intervention group, and the difference of nausea and vomiting before and after administration of aromatherapy in control group. The results were as follow:

Table 2 describe the difference between nausea and vomiting before and after administration of ginger aromatherapy in intervention and control group using Wilcoxon
Test.

Table 2 showed that 20 respondents of intervention group experienced reduction of nausea, 23 respondents experienced reduction of vomiting, 9 respondents experienced equal nausea, and 7 respondents experienced equal vomiting. Only 1 respondent experienced increase of nausea. According to these results, we concluded that there was a significant difference of nausea and vomiting frequency between before and after administration of aromatherapy. In control group, 2 respondents experienced reduction of nausea and vomiting, 25 respondents experienced equal nausea and vomiting, and 3 respondents experienced increase of nausea and vomiting. According to these results, we concluded that there was no significant difference of nausea and vomiting frequency in control group.

Table 3 showed difference of nausea and vomiting score between intervention and control group using Mann Whitney test. Result of analysis of difference between both groups presented in table 3.

Nausea and vomiting can be a physiological experience for every people in particular life stage with difference cicumstances (Palatty, 2013). Nausea and vomiting is a common complication which usually occurs as side effect from medicines, diseases, post operative complication,

Table 1. Description of Nausea and Vomiting Before and After Administration of Aromatherapy in Intervention and Control Group.

\begin{tabular}{llll}
\hline Characteristics & Median & Minimum & Maximum \\
\hline Intervention Group & & & \\
Nausea before administration of aromatherapy & 2.5 & 1 & 20 \\
Vomiting before administration of aromatherapy & 3 & 1 & 20 \\
Nausea after administration of aromatherapy & 1.5 & 0 & 15 \\
Vomiting after administration of aromatherapy & 1 & 0 & 15 \\
& & & \\
Control Group & & & \\
Nausea previously & 2 & 1 & 12 \\
Vomiting previously & 2 & 1 & 10 \\
Nausea thereafter & 2,5 & 1 & 10 \\
Vomiting thereafter & 2 & 0 & 10 \\
\hline
\end{tabular}

Source: data of 30 respondents from each group 
Table 2. Difference of Nausea and Vomiting Before and After Administration of Aromatherapy in Intervention and Control Group.

\begin{tabular}{llll}
\hline Variable & Result & Frequency & Signification \\
Intervention Group & & & \\
Nausea after administration of aromatherapy & Negative & 20 & 0,000 \\
& Positive & 1 & \\
& Ties & 9 & \\
Vomiting after administration of & Negative & 23 & \\
aromatherapy & Positive & 0 & \\
& Ties & 7 & 0,279 \\
Control Group & & & \\
Nausea post & Negative & 2 & \\
& Positive & 3 & 0,276 \\
Vomiting post & Ties & 25 & \\
& Negative & 2 & \\
& Positive & 3 & \\
& Ties & 25 & \\
\hline
\end{tabular}

Source: data of 30 respondents from each group

Table 3. Difference between Intervention and Control Groups

\begin{tabular}{llll}
\hline Variable & Group & Mean ranks & $\mathrm{P}$ \\
\hline Nausea & Intervention & 24.23 & 0.005 \\
Nausea & Control & 36.77 & \\
Vomiting & Intervention & 25.03 & 0.013 \\
Vomiting & Control & 35.97 & \\
\hline
\end{tabular}

Significant level: $\alpha: 0.05$

pregnancy symptom or, chemotherapy. But then, patients who get nauseous are sometimes accompanied by vomiting. Vomiting or emesis is a condition caused by strong contraction of abdominal muscle which propels abdominal content to come out from mouth, either with or without preceded by nausea. Nausea and vomiting often occur together in numerous condition, particularly as side effects from antineoplastic medicine utilization. Nausea and vomiting which occurred after chemotherapy are known as Chemotherapy Induced Nausea and Vomiting (CINV) (Palatty, 2013).

Chemotherapeutic agents stimulate enterochromaffin cells in the gastrointestinal tract to release serotonin, which activates serotonin receptors. Activation of the receptor activates vagal afferent pathway, which activates the vomiting center and cause emetic response. The released serotonin will activate 5-HT3 receptors of the vagus nerve and splanchnic nerve afferent fibers which then carry sensory signals to the medulla resulting in vomiting response.

Nausea and vomiting are common early manifestations of toxicity from chemotherapy drugs. Nausea associated with the movement of the stomach, is a complex movement in the abdominal cavity and the muscles in the chest cavity. While vomiting is the expulsion of the stomach contents forcefully, due to the gastrointestinal peristaltic, it requires 
coordinated contraction of the abdominal muscles, the pylorus, and antrum, cardiogastric rise, pressure reduction, and esophageal dilatation.

Reflex that induces vomiting caused by stimulation of receptors in the CNS, and or gastrointestinal. These receptors send a message to 14 area in the vomiting center of the medulla, which then coordinated with the action of vomiting. Vomiting induced by various chemicals, cytostatic drugs, and radiation are mediated through the Chemoreceptor trigger zone (CTZ).

CTZ located in the medulla, acts as chemical sensor and directed to the blood and CSF. This area is rich of various neurotransmitter receptors, such as cholinergic and histamine receptors, dopaminergic, opiate, serotonin, neurokinin, and benzodiazepines. Chemotherapeutic agents, metabolites, or any other emetic component induces vomiting process through one or more of these receptors.

Vomiting center receives stimulation from CTZ, the limbic system, cortex, vestibular system and the gastrointestinal system through afferent nerve fibers. The stimuli then responded by efferent nerve fibers of the vagus nerve. At the same time, the vomiting center stimulates sympathetic and autonomic reflex that accompanies nausea and vomiting such as vasoconstriction, tachycardia, diaphoresis, abdominal muscles and diaphragm contraction, and intestinal peristalsis. This process involves several neurotransmitters and chemoreceptor. The side effects of nausea and vomiting due to chemotherapy involve multiple receptors with complex pathophysiology.

Klein and Griffiths (Montazeri, 2013) mentioned that nausea and vomiting were the typical side effects from chemotherapy and reported to reach $54-96 \%$ of patients. More than $70 \%$ of patients were claiming, that they still experiencing nausea and vomiting after chemotherapy, eventhough anti-nausea drugs was already given. Nausea or vomiting occurred in $80 \%$ of patients undergoing chemotherapy. In addition, the interviews results showed that the experience of nausea and vomiting varies from 1 week to 10 days post chemotherapy.

This study showed that all respondents get the same chemotherapy drug, which is
PAXUS- Cisplatin and $5 \mathrm{FU}$, as well as the same nausea drug, namely ondansetron, and dexamethasone.

Cisplatin or Cisplatinum or cisdiammine dichloroplatinum (II) is a platinum metal based cancer chemotherapy drug. The platinum derivative compounds that show antitumor or anticancer properties has been widely synthesized. Cisplatin is a chemotherapeutic agent or a cancer drug that is highly effective and widely used. Based on statistics from the National Cancer Institute in 2013, Cisplatin were proven enable to cure patients of cervical cancer by up to $62 \%$. But ciplastin has some side effects such as nausea, vomiting, and impaired toxicity. Nausea and vomiting due to ciplastin administration can manifest up to 1 week after treatment. The incidence of nausea and vomiting caused by cytostatic agent is influenced by the level of each drug cytostatic emetogenicity. Based on the National Comprehensive Cancer Network (NCCN) in 2007, cisplatin is in a group of cytostatic drugs with emetogenic level of 4 , which means the emetic side effect is $>$ $90 \%$, while 5 fluorouracil drug is at the level 2 (10-30\%). Some chemotherapy agents such as cyclophosphamide, and cisplatin can induce incident of Chemotherapy Induced Nausea and Vomiting (CINV), which can reach $90 \%$ (Herrstedt, 2007).

The effect of chemotherapy drug cisplatin in addition to causing nausea, and vomiting can also cause toxicity. Nausea, and vomiting in cancer patients that receive chemotherapy treatment are caused by the stimulation of the vomiting center in CTZ as a side effect of chemotherapy drugs and a manifestation of a complex neural reflex. It has been known that there are two centers of nausea and vomiting. The first one is the vomiting center located in the medulla oblongata, and the second one is the CTZ located in the postrema area in the rear boundary of 4 th ventricle, with rich vascularization. CTZ is outside the blood brain barrier system, and can be stimulated directly by stimulating and dangerous substances, such as chemotherapy drugs, and its metabolites or other humoral stimuli.

The vomiting center receives stimulation from CTZ, limbic system, cortex, vestibular system, and gastrointestinal system through 
afferent nerve fibers. The excitatory then responded via efferent vagus nerve fibers. Simultaneously, vomiting center stimulates autonomic and sympathetic reflexes that accompanies nausea and vomiting such as vasoconstriction, tachycardia, diaphoresis, abdominal muscles, and diaphragm contraction, and intestinal peristalsis. This process involves several neurotransmitters and chemoreceptors.

As described in Table 2, twenty respondents who were given ginger aromatherapy felt their nausea was relieved, nine respondents still had the same nausea and only one respondent felt increased nausea. Still on the same table, 23 respondents experienced less vomiting, and 7 respondents still experienced vomiting. From the Wilcoxon test results, we can conclude that there was a difference of nausea and vomiting experience before and after administration of aromatherapy ( $p$-value $0.000)$ in the treatment group. Meanwhile, still from Table 2, it is explained that 2 respondent experienced no nausea, 25 respondents still experienced same nausea, and 3 respondents experienced an increased in nausea. Two respondents experienced less vomiting, 25 respondents still experienced vomiting, and 3 respondents experienced increased vomiting. The Wilcoxon test results showed p-value of 0.279 for nausea and 0,276 for vomiting, so it can be concluded that there was no difference in nausea, vomiting on measuring pre and post treatment of control group.

Respondents in this study get the same drugs for nausea and vomiting which are ondansetron and dexamethasone. Ondansetron is 5 -HT3 receptor antagonists that selectively inhibit serotonin receptors on the presynaptic vagus nervesensorsin the bowel wall, which work by selectively inhibit the 5 -hydroxytriptamine serotonin (5HT3) binding to its receptor in the $\mathrm{CTZ}$ and in the gastrointestinal tract. Serotonin 5-hydroxytriptamine (5HT3) is a substance released as response of toxins in gastrointestinal tract, will binds to its receptor and stimulates the vagal nerve to deliver stimulation to the CTZ, and vomiting center, eventually will induce nausea and vomiting.

Dexamethasone is a corticosteroid that shows good efficacy for the prevention of acute and delayed nausea and vomiting experience due to cytotoxic drug. In addition to the effect of an anti-emetic (ondansetron and dexamethasone) the decrease of nausea and vomiting also occur through other interventions such as the administration of ginger aromatherapy through mask inhalation because of its antiemetic effect. Better outcome was obtained due to the combination of antiemetics and other nursing interventions with various mechanisms of action.

Ginger aromatherapy administered through inhalation mask is one of the alternative actions that can be given to the patients to reduce post-chemotherapy nausea and vomiting. The aromatherapy could enter the body in one step with ease through the lungs, then flows into the blood vessels through the alveoli. Inhalation method performed in this study is by putting in 5 drops of aromatherapy oil in the mask and then applied it on the patient for about 10 minutes. Other ways of giving aromatherapy are with a tissue or cotton rolls by dropping 1- 5 drops of etheric oil onto a tissue or cotton rolls that's inhaled for 5-10 minutes.

Aromatherapy ingredient mechanism of action is through the body's circulatory system and the olfactory system. When taken orally or applied on the skin surface, etheric oil will be absorbed to the body through ingestion and skin absorption by capillaries, which would then be carried by the circulatory system to either blood circulation or lymphatic circulation. The capillary vessels then will circulate the substances to the central nervous system and the brain will deliver the message to the organ target. The etheric oils applied with massage will further stimulate the circulatory system to work vigorously. According to Buckle in Arwani (2011), aromatherapy oils easily enter the body in one easy step, from the lungs, then circulated through the blood vessels via alveoli. Olfactory organ is the only sensory sense with various nerve receptors that directly connects to outer world from the brain. Approximately with only 8 molecules presence, it could trigger electrical impulses on the nerve endings, while it takes approximately 40 stimulated nerve endings before someone aware of the scents they smell.

Aromatherapy works by affecting the brain, stimulated olfactory nerves by the 
presence of a particular scent linked directly to the hypothalamus. The hypothalamus is a part of the brain that control glandular system, regulates hormones, and affect the growth, and activity of the body. Aromatherapy administered through olfaction gives faster effect than any others mechanism.

Scent is a volatile molecule in the air; it will be interpreted by the brain as the sense of smell, if it enters the nasal cavity through inhalation. Olfactory process is divided into three stages; starts with the reception of the scent molecules by the olfactory epithelium, which is a receptor that contains 20 million nerve endings. Then, the smell will be transmitted as a message to the olfactory center located on the back of the nose (Howard, 2007). Vibrating hairs inside the nose will acts as a receptor and will deliver electrochemical messages to the emotional and memory center of a person, furthermore will deliver feedback to the entire body via the circulatory system.

In the olfactory center, neuron cells will interpret the scent and drove them to the limbic system which would then be sent to the hypothalamus to be processed. Messages that are delivered to the whole body will be converted into an action with the release of neurochemical substances such as feeling happy, relaxed, calm or passionate, including a decrease in nausea experience. Through inhalation, aromatic molecules will enter the lungs, and absorbed by the mucous lining of the respiratory tract, both on the bronchi and bronchioles. At the time the gas exchanges occurs in the alveoli, the molecule will be transported by the blood circulation in the lungs. Deep breathing will increase the amount of aromatic substances into the body. The scent response will stimulate the brain neurochemical cell. For example, a fragrant scent will stimulate the thalamus to secrete enkephalins which serves as natural painkillers, produces a calming effect, and decreases nausea (Howard, 2007).

The pituitary gland is also releasing a chemical agent into the blood circulation to regulate the function of other glands such as thyroid and adrenal glands. The scent that creates calm feeling will stimulate regions of the brain called the raphe nucleus to release serotonin that induce sleep (Howard, 2007).
Aromatherapy oils have some advantages as supportive treatments. According to Maifrisko in Arwani (2011), some advantages of aromatherapy by its type for example, rosemary will increase alertness, and improve memory, lemon scents aromatherapy will induce calm feeling, and peppermint aromatherapy will reduce nausea, and vomiting in pregnant women. Lemon aromatherapy administered by inhalation, is effective in reducing nausea, and vomiting in pregnancy (Parisa, 2014).

In this study, aromatherapy oils used was ginger etheric oil. Rhizome contains 0.6 to $3 \%$ of etheric oil containing $\alpha$-pinene, $\beta$ fellandren, borneol, camphene, limonene, linalool, citral, nonilaldehyde, desilaldehyde, methyl heptenone, sineol, bisabolene, $1-\beta$-curcumen, farnesene, humulene, $60 \%$ zingiberen and volatile zingiberole (spicy substance gingerol namely: (6)-gingerol 60-85\%; (4)-gingerol; [8]-gingerol 5-15\%, [10]-gingerol 6-22\%; (12)-gengerol; (6)-metilgingerdiol; Zogaol, Zingeron; (6) -Gingerdiol; (8)-Gingerdiol; (10)-Gingerdiol; Diarilheptanoida, Diaryl3-hydroxy-5-heptanone, aryl-curcumen, -bisabolon, (E)-farnesene. It also contains other aetheric oil, such as zingiberene, B-bisabolene, singiberol, zingiborenol, ar-curcumene and some aldehyde. Meanwhile, antiemetic effect is a result of zingeron and Zogaol substances (shogaol). Ginger contains etheric oils, gingerol, zingeron, resin, starch, and sugar. Its rhizome may be used as a cough medicine, antinausea, and colds and bloating therapy. The concentration of the active substance (gingerol and shogaols) may vary in each preparation method and may influence on the drug benefit significantly (Baliga, 2011).

Ginger has 2 groups of compounds based on their volatility properties, i.e. groups of volatile and non-volatiles compounds. Compound that produces hot sensation mentioned were non-volatile one. Etheric oil is a volatile compound, so it can be wafted by us. It also causes a distinctive ginger flavor. Etheric oils in ginger is a combination of terpenoid compounds consisting of the sesquiterpene, zingiberene, bisabolena, cineol, citral, zingiberal (some are called zingiberol, but both are different compounds; zingiberal containing the aldehyde group, while zingiberol group 
containing hydroxide, -OH), phellandrena, borneol, sitronellol, geranial, linalool, limonene, champene. Aetheric oils concentration in ginger is between 1 to $3 \%$.

Ginger contains protease and lipase that helps the body digests and absorbs food. Ginger may also reduce nausea from the effect of chemotherapy. Ginger aromatherapy is safe for use as an alternative therapy for nausea and vomiting associated with pregnancy, chemotherapy, and post-surgery (Pallaty, 2013). Antiemetic effect of ginger works by accelerating the absorption. Ginger also contains glycerol which can block serotonine. Serotonine is a neurotransmitter that synthesized at the serotonergic neurons on the central nervous system (CNS) and enterocromafin cells on the digestive tract, so it is believed, that it can give a comfortable feeling in the stomach, so it relieves nausea and vomiting. Gingerol and shogaol is an antiemetic that works similar with 5HT3 antagonists (Inaki, 2016). Serotonin 5-hydroxytriptamine (5HT3) is a substance that would be released if there are toxins in the gastrointestinal tract, binds to its receptor and stimulates the vagus nerve and deliver the stimulation to the CTZ, and vomiting center, then nausea and vomiting occur. A 5HT3 receptor antagonist inhibits the serotonin receptors in CNS and gastrointestinal tract. This medicine is used to treat post-operative nausea and vomiting caused by cytotoxic drugs. In addition, shogaols and gingerol also have antihistamine properties.

Ginger aromatherapy has several benefits including relieving nausea and vomiting during pregnancy, travel, and postoperative. Ginger is a rhizome plants which are common as a spice and ingredient for herbal medicine to treat a variety of diseases, especially gastrointestinal complaints such as nausea, vomiting, diarrhea, arthritis, muscle pain and fever (Ali, 2008). Apart from being anti-nausea and antiemetics properties, ginger also has efficacy as an antioxidant, anti-inflammatory and antimicrobial.

Table 5 shows the mean ranks scores of nausea in intervention group (24.23) and control group (36.77). While the mean ranks score of vomiting in intervention group was 25.03 and control group was 35.97. From these results, difference between the scores of nausea in intervention group and control group was statistically significant ( $p$-value; 0.005 ), and difference between vomiting score in intervention group and control group was also statistically significant ( $p$-value: 0.013 ). It can be concluded that ginger aromatherapy had a sginificant effect on chemotherapy-induced nausea and vomiting patients. Boiled ginger had significant effect in reducing nausea and vomiting after breast cancer chemotherapy. Alparslan (2012), also found a significant difference of reducing nausea and vomiting effect between intervention group and control group. Alparslan used $2 \times 400 \mathrm{mg}$ ginger capsule as an intervention every morning and evening from when the patients visited outpatient clinic until the completion of chemotherapy cycle. The results showed ginger can reduce the severity and duration of nausea in cancer patients after chemotherapy.

A study conducted by Levine (2008), with 28 cancer patients received chemotherapy divided into three groups, first group received a moderate protein diet and ginger, second group received high protein diet and ginger, third group received a normal diet. The results showed that foods containing high protein and ginger reduced nausea caused by chemotherapy compared with two other groups. It is believed the decrease of nausea and vomiting is due to the effects of ginger that works with antiemetics synergically. Foods with high proteins and ginger will reduce nausea and reduce antiemetic use.

Lua (2015), conducted a study about the effectiveness of ginger aromatherapy by inhalation toward chemotherapy-induced nausea and vomiting with quality of life in breast cancer patients. The study stated that out of 60 respondents said that scores of nauseas was significantly lower after given the aetheric oils of ginger by inhalation compared to the group who were given a placebo in the acute phase $(p$-value $=0.040)$. However, it did not have continuous effect on long term treatment in general, and had no effect in preventing vomiting. Enikmawati (2016), stated in her study that the average frequency of nausea and vomiting in the intervention group is lower than control group, so it can be concluded 
that ginger aromatherapy can reduce the frequency of nausea and vomiting associated with chemotherapy on breast cancer patients. Ryan (2012), conducted a study to 576 cancer patients that were given intervention 2 times for 6 days starting at $3^{\text {rd }}$ day before chemotherapy, divided into four group: (1) placebo, (2) 0.5 grams of ginger, (3) 1 gram of ginger, (4) 1.5 grams of ginger and anti-vomiting treatment (5HT3 receptor antagonists). The results showed that all concentrations of ginger significantly reduced the incidence of acute nausea but not the delayed one, with effective concentration of 0.5 gram and 1 gram.

In general, the treatment of postchemotherapy induced nausea and vomiting are combination of serotonin (5-HT3) receptor antagonist, dexamethasone, and neurokinin-1 (NK1). Ginger works as 5-HT3 antagonist (Ryan, 2010). As an anti-nausea and anti-emetic, ginger works in several ways. First, it works by modulating the effects on gastrointestinal tract such as stimulating motility, saliva, and bile secretion. Second by inhibiting 5 -HT3, it has effect similar to antagonist 5- HT3 and ondansetron that cause the stomach to contract, causing nausea and vomiting. Third, by inhibiting the carminative effects, thus preventing stomach gas release. Fourth, by reducing the effects of cisplatin as chemotherapy. Fifth, it has the effect smiliar to dimenhydrinate (Siti Masruroh, 2016).

Dimenhydrinaste is a histamine antagonist (H1) and vestibular stimulation system inhibitor that works on otolith and if delivered in large dose will affect semicircular canal. Sixth, ginger can reduce the effects of cisplatin through inhibition of central or peripheral nervous by increasing 5 hydroxytryptamin, dopamine, and substance P. Cisplatin is a drug-inducing nausea and vomiting in chemotherapy.

Besides ginger effectiveness in reducing nausea and vomiting post chemotherapy, it also reduces nausea and vomiting due to pregnancy. Some studies of ginger extract to reduce nausea and vomiting in pregnancy such as provision of $250 \mathrm{mg}$ ginger containing capsules given four times a day in 4 days showed that ginger effectively reduce nausea compared to the placebo group (Ozgoli, 2009).
Basirat's study, 2009 (citation Inake Lete, 2016) with administration of $500 \mathrm{mg}$ ginger biscuits 5 times a day in 4 days showed that ginger was effective in relieving nausea and reduce vomiting compared to placebo group. A study conducted by Ghani (2013), mentioned that the episodes of nausea and vomiting in early pregnancy decreased after administration of aromatherapy by inhalation for 3 days

Another study conducted by Fatemeh (2015), toward 50 patients after open nephrectomy surgery and 50 patient postoperative nephrectomy laparoscopy, concluded that the essence of ginger was effective in reducing nausea and vomiting, not only in patients with open nephrectomy $(p=0.001)$ but also postoperative laparoscopic nephrectomy patients $(p=0.001)$ compared to placebo group.

\section{Conclusion}

This study concluded that nausea and vomiting incidence differ before and after administration of aromatherapy ( $p$-value 0.000) in intervention group. While, Wilcoxon test results of control group for nausea $(p$-value $=0.279)$ and vomiting $(p$-value $=0,276)$ showed no difference in nausea and vomiting before and after measurement. Results of Mann Whitney test showed significant difference in intervention group and control group on the nausea score ( $p$-value: 0.005$)$, and the vomiting score ( $p$-value:0.013). Therefore, it can be concluded that ginger aromatherapy has effects on relieving nausea and vomiting in chemotherapy cancer patients.

Substances contained in ginger is useful in reducing chemotherapy-induced nausea. As an anti-nausea and anti-emetic, ginger works in several ways. First, it works by modulating the effects on gastrointestinal tract such as stimulating motility, saliva and bile secretion. Second by inhibiting 5-HT3, it has effect similar to antagonist 5- HT3 and ondansetron that cause the stomach to contract, producing nausea and vomiting experiences. Third, by inhibiting the carminative effects, thus preventing stomach gas release. Fourth, by reducing the effects of cisplatin as chemotherapy. Fifth, it has the effect similar to dimenhydrinate.

Hospital recommendation from this study is: this study can be used as a 
consideration for determining the alternatives action in reducing nausea and vomiting in chemotherapy patient.

\section{References}

Ali, BH., et al. 2008. Some Phytochemical, Pharmacological and Toxicological Properties of Ginger (Zingiber officinale Roscoe): a review of recent research. Food Chem Toxicol, 46 (2) : 409-20

Alparslan, G.B., et al, (2012), Effect of Ginger on ChemotherapyInduced Nausea and/or Vomiting in Cancer Patients. Journal of the Australian - Traditional Medicine Society, 18 (1)

Arwani, Sriningsih I, Hartono R. 2012. Pengaruh Pemberian Aromaterapi terhadap Tingkat Kecemasan Pasien Sebelum Operasi dengan Anestesi Spinal di RS Tugu Semarang. Jurnal Riset Kesehatan, 2 (2)

Baliga MS, Haniadka R, 2011. Pereira MM, et al. Update on the Chemopreventive Effects of Ginger and its Phytochemicals. Critical Reviews in Food Science and Nutrition, 51 (6) : 499-523.

Enikmawati, A. 2016. Pengaruh Aromaterapi Jahe terhadap Mual Muntah Akibat Kemoterapi Pada Klien Kanker Payudara di Rumah Sakit PKU Muhammadiyah Surakarta, Digital Repository : Universitas Muhammadiyah Yogyakarta.

Fatemeh Sadat Hosseini, Mohsen Adib-Hajbaghery. 2015. Ginger Essence Effect on Nausea and Vomiting After Open and Laparoscopic Nephrectomie. Nurs Midwifery Stud, 4 (2)

Ghani., R.M.A, \& Ibrahim., A.T.A. 2013. The Effect of Aromatherapy Inhalation on Nausea and Vomiting in Early Pregnancy: A Pilot Randomized Controlled Trial,Journal of Natural Sciences Research, 3 (6)

Herrstedt J, Dombernowsky P. Anti-emetic therapy in cancer chemotherapy: current status. Basic Clin Pharmacol Toxicol, 101 (3) : 143-50

Howard S, Hughes BM, Expectancies. 2007. Not Aroma, Explain impact of Lavender Aromaterapy, New England Journal of Medicine, 5 (365) : 479-485

Inaki Lete and Jose Allue. 2016. The Effectiveness of Ginger in the Prevention of Nausea and Vomiting during Pregnancy and Chemotherapy. Integrative Medicine Insights, $20(16): 11$

Montazeri AS., et al. 2013. Effect of Herbal Therapy to Intensity Chemoterapy-Induced Nausea and Vomiting in Cancer Patients., Iranian Red Crescent Medical Journal (IRCMJ),15 (2), : 101-106

Mulyati S, Oki Suwarsi, Insi Farisa Desy Arya. 2015. Pengaruh Media Film Terhadap Sikap Ibu Pada Deteksi Dini Kanker Serviks. KEMAS, $11(1)$

Levine, M.E., et al. 2008. Protein And Ginger Fort He Treatment Of Chemotherapy-Induced Delayed Nausea. The Journal of Alternative and Complementary Medicine, 14 (5)

Lua PL, Salihah N, Mazlan N. 2005. Effects of Inhaled Ginger Aromatherapy on Chemotherapyinduced Nausea and Vomiting and Healthrelated Quality of Life in Women with Breast Cancer. Pubmed, 23 (3) : 396-404.

Palatty PL., et al. 2013. Ginger in the prevention of nausea and vomiting: a review. Critical Reviews in Food Science and Nutrition, 53(7) : 659-69

Parisa YK, et al. 2014. The Effect of Lemon Inhalation Aromatherapy on Nausea and Vomiting of Pregnancy: A Double-Blinded, Randomized, Controlled Clinical Trial, Iranian Red Crescent Medical Journal, 16 (3)

Ryan JL. 2012. Treatment of chemotherapy-induced nausea in cancer patients. Europian Oncology, 6 (2): $14-16$

Ryan JL, Heckler CE, Roscoe JA, et al. 2010. Ginger (Zingiber officinale) Reduces Acute Chemotherapy-Induced Nausea: a URCC CCOP study of 576 patients. Support Care Cancer, 20 (7) : 79-89

Siti Masruroh dan Anggraeni Janar Wulan. 2016. Khasiat Jahe (Zingifer Officinale) untuk Mengatasi Mual Muntah pada Wanita Hamil. Majority, 5 (1)

Susanti L dan Tarigan M. 2012. Karakteristik Mual dan Muntah Serta Upaya Penanggulangan oleh Penderita Kanker yang Menjalani Kemoterapi, FK Unsu. 